\title{
A Mesophilic Aeromonas salmonicida Strain Isolated from an Unsuspected Host, the Migratory Bird Pied Avocet
}

\author{
Antony T. Vincent ${ }^{1}$, Alex Bernatchez ${ }^{2,3,4}$, Joachim Frey ${ }^{5}$ and Steve J. Charette ${ }^{2,3,4, *}$ \\ 1 INRS-Institut Armand-Frappier, Bacterial Symbionts Evolution, Laval City, QC H7V 1B7, Canada; \\ antony.vincent@iaf.inrs.ca \\ 2 Institut de Biologie Intégrative et des Systèmes, Pavillon Charles-Eugène-Marchand, Université Laval, \\ Quebec City, QC G1V 0A6, Canada; abernatchez1@outlook.com \\ 3 Centre de Recherche de l'Institut Universitaire de Cardiologie et de Pneumologie de Québec, Quebec City, \\ QC G1V 4G5, Canada \\ 4 Département de Biochimie, de Microbiologie et de Bio-Informatique, Faculté des Sciences et de Génie, \\ Université Laval, Quebec City, QC G1V 0A6, Canada \\ 5 Vetsuisse Faculty, University of Bern, CH-3001 Bern, Switzerland; joachim.frey@vetsuisse.unibe.ch \\ * Correspondence: steve.charette@bcm.ulaval.ca; Tel.: 1-418-656-2131 (ext. 406914)
}

Received: 22 August 2019; Accepted: 15 November 2019; Published: 20 November 2019

\begin{abstract}
Aeromonas salmonicida is a Gram-negative bacterium, known as a fish pathogen since its discovery. Although the species was initially considered psychrophilic, a mesophilic subspecies (pectinolytica) and many other mesophilic strains still not attributed to subspecies have been described in the last two decades. These mesophilic strains were sampled from various sources, including humans, and some of them are known to be pathogenic. In this study, we describe a strain, JF2480, which was isolated from the spleen, and also found the kidney and liver of a dead pied avocet (Recurvirostra avosetta), a type of migratory bird inhabiting aquatic environments. A core genome phylogenomic analysis suggests that JF2480 is taxonomically distant from other known A. salmonicida subspecies. The genome sequence confirms that the strain possesses key virulence genes that are present in the typical A. salmonicida psychrophilic subspecies, with the exception of the genes encoding the type three secretion system (T3SS). Bacterial virulence assays conducted on the surrogate host Dictyostelium discoideum amoeba confirmed that the strain is virulent despite the lack of T3SS. Bacterial growth curves showed that strain JF2480 grow well at $40^{\circ} \mathrm{C}$, the body temperature of the pied avocet, and even faster at $41^{\circ} \mathrm{C}$, compared to other mesophilic strains. Discovery of this strain further demonstrates the extent of the phylogenomic tree of this species. This study also suggests that A. salmonicida can infect a wider array of hosts than previously suspected and that we need to rethink the way we perceive A. salmonicida's natural environment.
\end{abstract}

Keywords: Aeromonas salmonicida; mesophile; bird; pied avocet; Dictyostelium discoideum; pathogenesis

\section{Introduction}

Aeromonas salmonicida is a Gram-negative bacterium, which is ubiquitous in aquatic environments. This species is divided into five officially recognized subspecies: salmonicida, smithia, achromogenes, masoucida, and pectinolytica [1]. Strains of the subspecies salmonicida, smithia, achromogenes and masoucida can infect a wide range of fish and are psychrophilic with their growth being limited to temperatures not higher than about $25^{\circ} \mathrm{C}$ [1-3]. In 2000, the pectinolytica subspecies was isolated directly from a polluted river (Matanza River, Argentina) without having any known host [4]. This subspecies grows at $37^{\circ} \mathrm{C}$ and is thus considered mesophilic. Some studies had previously reported the existence of 
mesophilic A. salmonicida strains, known as the hybridization group 3 [HG3], isolated from human and animal hosts [5-8]. However, the classification of these strains was made prior to the advent of DNA sequencing and we now know that biochemical approaches, compared to molecular ones, can sometimes lead to misclassifications for A. salmonicida [9]. Consequently, the finding of the subspecies pectinolytica was a major turning point for the taxonomy of $A$. salmonicida and suggested a greater diversity among the species of this bacterium.

Many new mesophilic A. salmonicida strains have been discovered and described especially in recent years. This was the case with the characterization of four Indian mesophilic $A$. salmonicida strains (Y47, Y567, Y577, A527) from undetermined subspecies and isolated from contaminated food [10-12]. Mesophilic A. salmonicida strains with human clinical background were also reported in Europe and India, including from a 68-year-old diabetic woman on continuous ambulatory peritoneal dialysis with abdominal pain and cloudy peritoneal fluid, in the blood of a 34-year-old female patient, from the skin infection of a 67-year-old immunocompetent male, in the right eye of a 55-year-old female who had recovered from cataract surgery, from a 15-year-old boy who had recovered from a finger surgery, from the feces of a child suffering from acute gastroenteritis, and finally from a person having cellulitis in a foot following trauma [13-18]. However, the pathogenicity of the isolates from human cases was not clearly demonstrated until a very recent study clearly showed the capacity of mesophilic A. salmonicida strains to infect mammals by doing infection experiments on mice [18].

The most recent phylogenomic analyses based on core genome revealed a great diversity in the mesophilic strains of the A. salmonicida species, opening the door to potentially more mesophilic subspecies than psychrophilic ones $[11,18]$. The increasing number of mesophilic strains also suggests the possibility to find other mesophilic A. salmonicida subspecies in unsuspected hosts.

In this study, we investigated the first case of bird infection by a mesophilic $A$. salmonicida strain. The strain was isolated from the spleen, and also found in the kidney and liver of a pied avocet (Recurvirostra avosetta) dead of sepsis. Pied avocets are migratory birds that feed in shallow lakes and mud ponds. The complete genome of this strain was sequenced and its growth capacity, virulence, and metabolic properties were investigated. This strain confirms the evolution of $A$. salmonicida species to infect three different classes of hosts (fish, mammals, and birds).

\section{Materials and Methods}

\subsection{Bacterial Strains and Growth Conditions}

A. salmonicida strains used in this study are described in Table 1 . The strain that was retained and kept as JF2480 was an isolated colony from the spleen culture of a dead pied avocet. The spleen, liver, and kidney isolates were verified as $A$. salmonicida by phenotypic tests and sequencing rrs (16S rRNA), gyr $A$, and $r p o B$ genes, but the latter two were not kept as they were identical to JF2480. When required for the experiments, the bacteria were thawed from glycerol 15\% stock and grown on tryptic soy agar (TSA) for one day at $37^{\circ} \mathrm{C}$ for the mesophilic strains, or three days at $18^{\circ} \mathrm{C}$ for the masoucida subspecies.

Table 1. A. salmonicida strains used in this study.

\begin{tabular}{ccccc}
\hline Name & Subspecies & Lifestyle & Origin & Reference \\
\hline JF2480 & N/A & Mesophile & Switzerland & This study \\
Y47 & N/A & Mesophile & India & {$[10]$} \\
Y567 & N/A & Mesophile & India & {$[10]$} \\
Y577 & N/A & Mesophile & India & {$[10]$} \\
A527 & N/A & Mesophile & India & {$[11]$} \\
34 mel $^{\mathrm{T}}$ & pectinolytica $^{\mathrm{T}}$ & Mesophile & Argentina & {$[4]$} \\
${\text { NBRC } 13784^{\mathrm{T}}}^{\text {masoucida }}$ & Psychrophile & Japan & {$[19]$} \\
\hline \multicolumn{5}{c}{ T: type strain. }
\end{tabular}




\subsection{DNA Extraction and Sequencing}

The total genomic DNA of strain JF2480 was extracted using DNeasy Blood and Tissue kits (Qiagen, Montreal, QC, Canada) with the addition of a RNase treatment step to the manufacturer's protocol. Sequencing was performed using a MiSeq (Illumina, San Diego, CA, USA) system at the Plateforme d'Analyse Génomique of the Institut de Biologie Intégrative et des Systèmes (Université Laval, Quebec City, QC, Canada).

\subsection{Sequence Assembly and Analyses}

The sequencing reads were de novo assembled using A5-miseq version 20160825 [20]. The draft genome was annotated by Prokaryotic Genome Annotation Pipeline (PGAP) [21] and deposited in DDBJ/ENA/GenBank under the accession number VOIP00000000. The sequencing reads were deposited in SRA under the accession number PRJNA264317.

Molecular phylogeny was used to determine the phylogenetic position of strain JF2480 among the other A. salmonicida. To do this, the genomic sequence of strain JF2480 was added to a dataset comprising a representative of each of the Aeromonas species, all sequences from mesophilic A. salmonicida and the sequences of representatives of all psychrophilic subspecies of $A$. salmonicida (Table S1) [18]. All the 55 genome sequences were annotated using Prokka version 1.13.3 [22]. Homologous links between the translated coding sequences were found using the combination of the two algorithms COG [23] and OMCL [24] through GET_HOMOLOGUES version 20190102 [25]. The 2018 gene sequences (excluding paralogs) corresponding to the softcore (sequences present in more than $95 \%$ of the genomes) were aligned by codons using mafft version 7.407 [26] through TranslatorX version 1.1 [27]. The resulting alignments were filtered using BMGE version 1.12 [28] and concatenated in a partitioned supermatrix using AMAS [29]. The evaluation of the best-fit model of each partition (Table S2) and the maximum-likelihood phylogeny were done using IQ-TREE version 1.6.10 [30,31]. The robustness of the tree was assessed by performing 10,000 ultrafast bootstraps [32]. The final tree has been midpoint rooted using FigTree version 1.4.3 (http://tree.bio.ed.ac.uk/software/figtree/). The Average Nucleotide Identity (ANI) values were computed for genome sequences of $A$. salmonicida using pyani (https://github.com/widdowquinn/pyani). The percentage of conserved proteins (POCP) were computed for each pair of genomes using the OMCL algorithm [24] through GET_HOMOLOGUES version 20190102 [25]. Genes unique to JF2480 were found using PATRIC [33] and those involved in secretion systems with TXSScan [34]. EggNOG-mapper was used to further annotate the genes [35].

\subsection{Virulence Assay}

The virulence of $A$. salmonicida can be determined by its capacity to resist to the predation of Dictyostelium discoideum amoebae [36]. The strain DH1-10 of D. discoideum was grown in a Petri dish at $21^{\circ} \mathrm{C}$ in HL5 liquid medium containing $15 \mu \mathrm{g} / \mathrm{mL}$ of tetracycline [37,38]. The D. discoideum cells were harvested, centrifuged, resuspended in HL5 without antibiotic, at the following concentrations: 100,000 cells $/ 5 \mu \mathrm{L}, 10,000$ cells $/ 5 \mu \mathrm{L}, 1000$ cells $/ 5 \mu \mathrm{L}, 100$ cells $/ 5 \mu \mathrm{L}, 10$ cells $/ 5 \mu \mathrm{L}$ and 0 cells $/ 5 \mu \mathrm{L}$. Single colonies from A. salmonicida strains and from Klebsiella aerogenes strain, used as non-pathogenic control, were resuspended in $300 \mu \mathrm{L}$ of tryptic soy broth (TSB) to an optical density of 0.4 at $595 \mathrm{~nm}\left(\mathrm{OD}_{595}\right)$ and $50 \mu \mathrm{L}$ of the suspension were deposited in the wells of a 24-well plate containing $2 \mathrm{~mL}$ of HL5 agar. The dried bacterial lawns were spotted with $5 \mu \mathrm{L}$ drops of $D$. discoideum cell suspension. The plates were incubated for 7 days at $18{ }^{\circ} \mathrm{C}$ and were then examined for the presence of phagocytic plaques [36].

\subsection{Growth Curve}

Bacteria from overnight growth on TSA at $37^{\circ} \mathrm{C}$ (for all bacteria except masoucida subspecies grown at $18{ }^{\circ} \mathrm{C}$ ) were resuspended in TSB. The turbidity was adjusted to an $\mathrm{OD}_{595}$ of 0.2 , and the cultures were incubated in 48 -well plate at $40^{\circ} \mathrm{C}$ or $41^{\circ} \mathrm{C}$ with shaking at $200 \mathrm{rpm}$ in a Tecan Infinite F200 PRO microplate reader (Tecan, Morrisville, NC, USA). The ODs were measured automatically 
every $15 \mathrm{~min}$ for $12 \mathrm{~h}$. Statistical significance between the growth curves was assessed using the compareGrowthCurves function of the R package statmod [39]. The $p$-values were adjusted for multiple testing using Holm's method as implemented in compareGrowthCurves

\section{Results}

An Aeromonas sp. isolate initially identified as Aeromonas hydrophila-like strain was isolated in 1998 from a dead pied avocet (Recurvirostra avosetta) (Figure 1) that lived in a pied avocet colony in an outdoor enclosure of the zoo of Bern (Switzerland). The bird was the only dead one found in the colony of which the other individuals showed no signs of disease. It was removed rapidly after death and had undergone standard necropsy by a veterinary pathologist at the Department of Infectious Diseases and Pathobiology, approximately $3 \mathrm{~h}$ after death. Other than a grossly enlarged spleen, the tissues were reported free of macro-parasites and other lesions. Bacterial analysis was made immediately after the necropsy. The Aeromonas sp. was isolated abundantly as virtually pure culture from the spleen, kidney, and liver shortly after the death of the animal, indicating its role as causative agent of septicemia and death of the bird. An isolate from the spleen named JF2480, was conserved and further characterized based on $r r s$ (16S rRNA) and rpoB sequence, which revealed that this bacterium was a member of the A. salmonicida species (data not shown). This was surprising since, to our knowledge, no case of bird infection by $A$. salmonicida has been reported so far. It was even more intriguing knowing that the body temperature of Recurvirostra avosetta is $40^{\circ} \mathrm{C}$ [40], a relatively high temperature for this bacterial species.

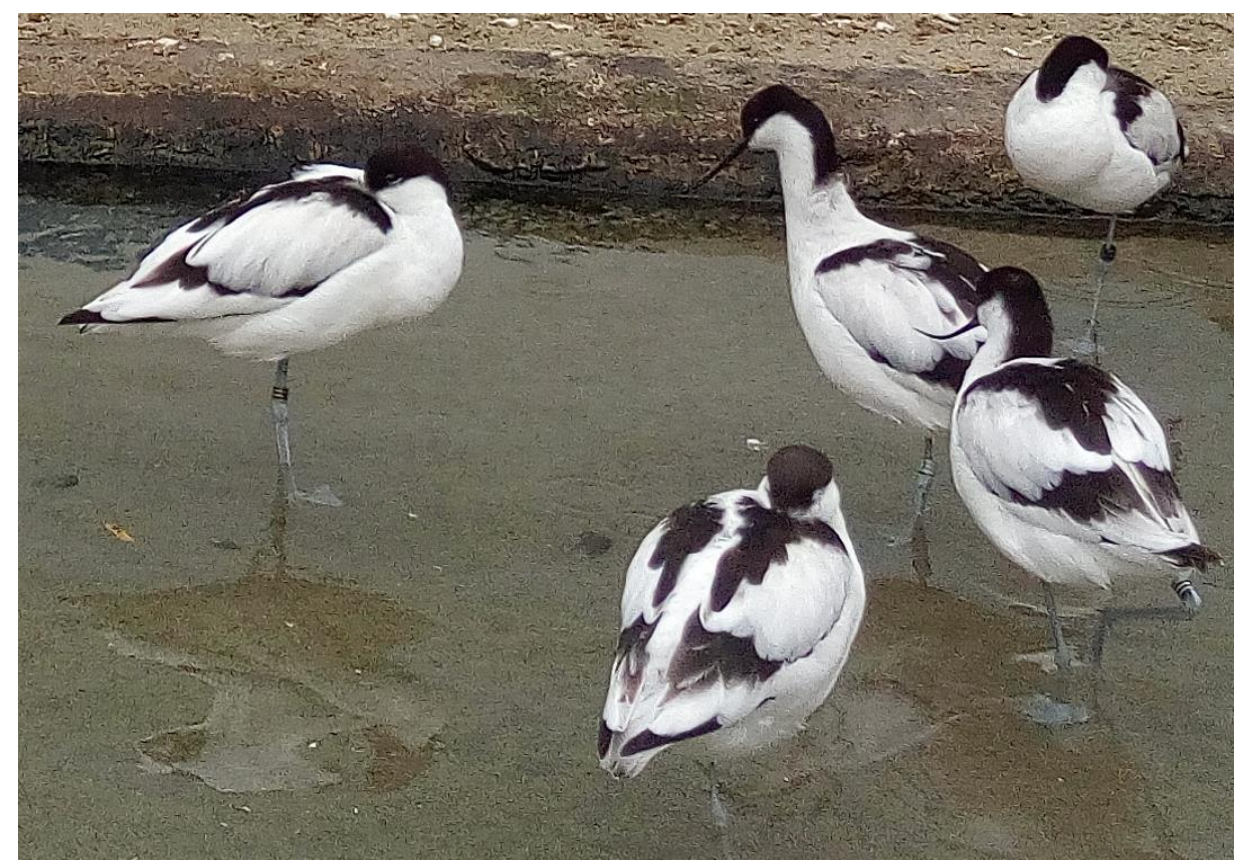

Figure 1. Pied avocets.

In order to have a clearer portrait of the identity of this bacterium, its genome was sequenced using the Illumina MiSeq technology. A robust phylogenomic analysis based on core genome was then performed to shed light on the phylogenetic relation between this unusual strain and the other A. salmonicida strains (Figure 2). Interestingly, its phylogenetic position is between the previously known mesophilic and psychrophilic strains. The ANI values confirm that it is, however, as distant as the previously known mesophilic strains, while all the psychrophilic strains are more closely related. To complement the ANI values, which permit us to measure the genetic distance in terms of nucleotide identity, the POCP values were also calculated. The POCP values, that reflect the level of conservation between different gene repertoires, clearly show that JF2480 is related to all other mesophilic strains. 
In addition to clustering all mesophilic strains together, the POCP values permit us to delineate the subspecies boundaries between psychrophilic subspecies [41]. Indeed, the different psychrophilic subspecies share $\sim 99 \%$ nucleotide identity between them, making their separation difficult based on this criterion alone. However, POCPs have values around $80 \%$, giving higher resolution than ANIs. This suggests a faster evolution of the gene repertoire in these subspecies compared to sequence evolution. This result is corroborated by various studies showing a high plasticity in the mobilome of $A$. salmonicida subsp. salmonicida and that this bacterium can easily acquire exogenous material by horizontal transfers [42-44].

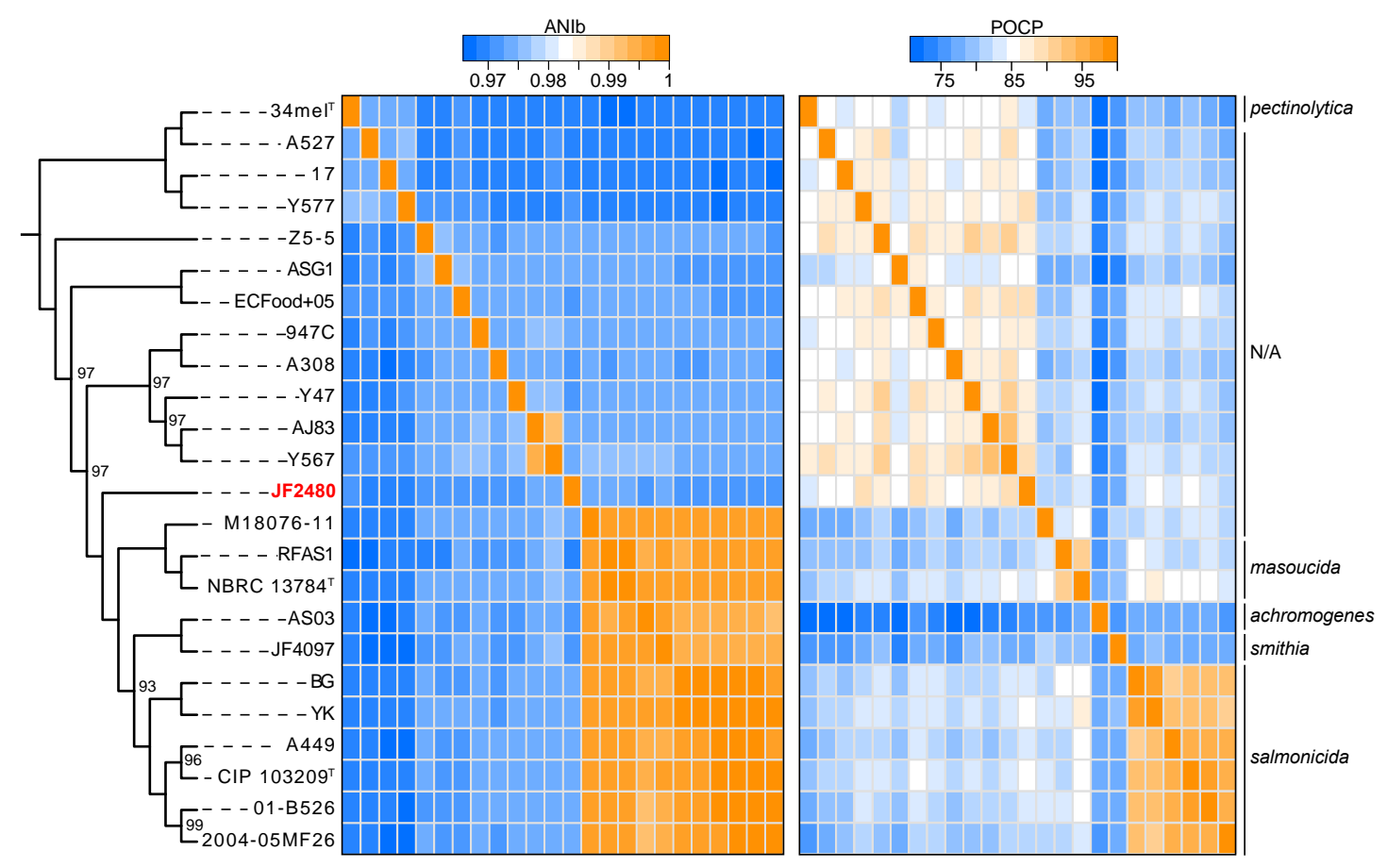

Figure 2. Cladogram showing the phylogenetic relations between JF2480 and other A. salmonicida strains. Only bootstrap values inferior to 100 are shown at the corresponding nodes. The heatmap represents the ANI values (in the middle) and the POCP values (on the right).

Given the unusual host, the genome sequence was an opportunity to investigate the virulence factors of the strain JF2480. Secretion systems are protein machineries important for bacterial virulence [45]. The genome of strain JF2480 was predicted to possess mandatory genes for T1SS, T2SS, T4P, Tad, and T6SSi. Although no core genes encoding for T3SS have been detected, two genes coding for effectors (AexT and AexU), known to be secreted by this system, were found.

In the past, it has been shown that bacteria without a functional T3SS and especially Aeromonas bacteria were not virulent when tested in the predation assay involving the soil amoeba $D$. discoideum used as a surrogate host $[36,46]$. A low quantity of amoebae was able to create a phagocytic plaque on K. aerogenes (the positive control) while only a high quantity of $D$. discoideum cells was required to observe amoebal growth on JF2480 (Figure 3). Thus, bacterial virulence assays conducted on JF2480 revealed that this strain is virulent when facing $D$. discoideum even in absence of a complete T3SS compared to K. aerogenes bacterium known to be totally avirulent [47]. Other mesophilic A. salmonicida strains do not possess a complete T3SS. It is the case, among others, of the strains Y567 and Y47 isolated in a food market in India [10] (Table 1). These two strains have also displayed a clear virulence against D. discoideum (Figure 3). 


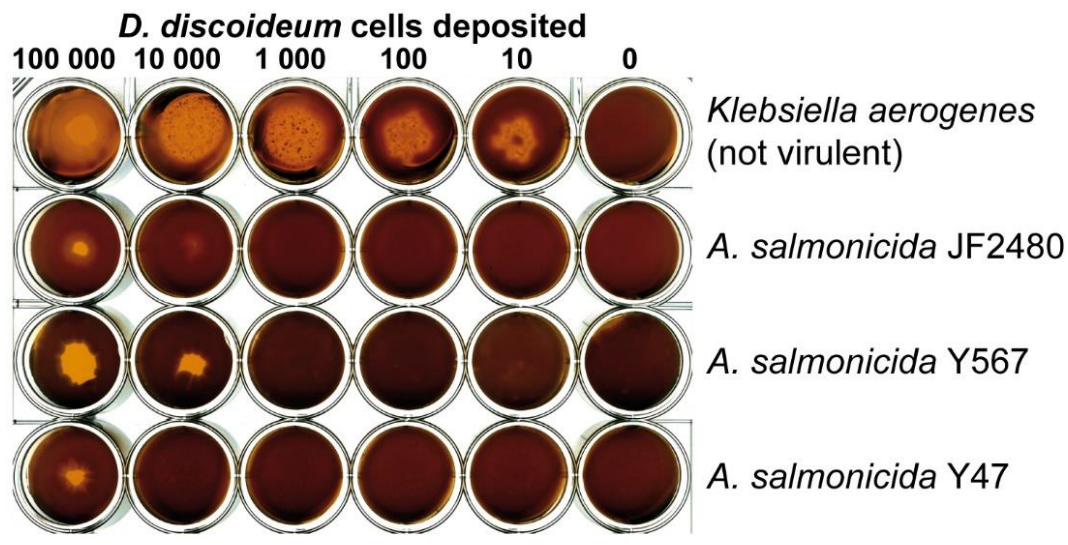

Figure 3. Virulence of strain JF2480 at low temperature. Different numbers of $D$. discoideum cells were deposited on a lawn of the different bacterial strains and grown on HL5 agar for 7 days at $18{ }^{\circ} \mathrm{C}$. This test has been performed three times (biological replicates) giving similar results each time.

A previous study that investigated the virulence of $A$. salmonicida from human clinical cases reported five genes uniquely found in mesophilic strains able to cause necrotizing fasciitis [18]. Two of these genes, encoding for a hemerythrin and a catalase, were confidently found in the genomes of JF2480, Y567, and Y47, which are virulent against D. discoideum (Table 2). Homologs of these two genes were already listed to be involved in the virulence of other bacteria $[48,49]$.

Table 2. Presence of the five genes putatively involved in necrotizing fasciitis.

\begin{tabular}{|c|c|c|c|c|}
\hline \multirow{2}{*}{ Protein } & \multirow{2}{*}{ Virulence Trait } & \multicolumn{3}{|c|}{ Strains $^{c}$} \\
\hline & & JF2480 & Y567 & Y47 \\
\hline $\begin{array}{l}\text { Two pore domain potassium } \\
\text { channel family protein }\end{array}$ & $\mathrm{N} / \mathrm{A}^{\mathrm{a}}$ & $40 \% \mathrm{~d}$ & $99 \%$ & $99 \%$ \\
\hline Hemerythrin & $\begin{array}{l}\text { A. hydrophila survival in host } \\
\text { macrophages }\end{array}$ & $98 \%$ & $98 \%$ & $98 \%$ \\
\hline $\begin{array}{l}\text { Pseudaminic acid } \\
\text { cytidylyltransferase }\end{array}$ & Colonisation of H. pylori & $99 \%$ & $50 \%{ }^{d}$ & $100 \%$ \\
\hline Catalase KatE ${ }^{\mathrm{b}}$ & $\begin{array}{l}\text { Virulence of Leptospira spp. in } \\
\text { animal models }\end{array}$ & $98 \%$ & $99 \%$ & $98 \%$ \\
\hline $\begin{array}{l}\text { UDP-N-acetylglucosamine-1- } \\
\text { phosphate transferase }{ }^{c}\end{array}$ & $\begin{array}{l}\text { Production of enterobacterial } \\
\text { antigen in S. enterica }\end{array}$ & $45 \% \mathrm{~d}$ & Absent & $61 \%^{d}$ \\
\hline
\end{tabular}

a: N/A, none-applicable; b: The catalase was annotated as KatE by PATRIC [33]; c: \% of similarity in regard to the virulent strain A. salmonicida 947 C; d: likely distant homologs.

Given the novelty of the host, it was relevant to investigate the genes unique to JF2480 to have clues about the genetic determinants that may be involved in its success of colonization. A total of 70 genes were found to be unique to JF2480 (Table S3). While several of them encode hypothetical proteins, others are related to mobile elements (phages and plasmids) and citrate metabolism. A gene encoding for a zonula occludens toxin-like (Zot) was also found. However, the gene is truncated in JF2480. By investigating the presence of this gene in other species of the genus Aeromonas, it has been possible to find that only Aeromonas rivuli has a homologue (Figure S1). The Zot toxin is known to be a virulence factor encoded in the genome of the lysogenic-filamentous phage CTXФ that is integrated in the genome of the human pathogen Vibrio cholerae [50]. The phage СТХ $\Phi$ also harbors genes producing the cholera toxin $(c t x A$ and $c t x B)$. These genes do not have clear homologs in the genome of JF2480, comparatively to the Zot toxin. Further research by performing TBLASTN analysis against a dataset containing representative genome sequences from all available Aeromonas species (Table S1), revealed a second gene encoding a putative Zot toxin, which this time seems complete. The distribution of this gene among Aeromonas is much more scattered than for the partial gene (Figure S1). For example, several mesophilic and psychrophilic strains of A. salmonicida possess an homologue of this gene. 
The amoeba predation assay has been performed at $18^{\circ} \mathrm{C}$ and not $37^{\circ} \mathrm{C}$ because $D$. discoideum cannot survive over $26^{\circ} \mathrm{C}$. The virulence of strain JF2480 at this temperature suggests that the bacterium can grow quite well at low temperature. To confirm it, the growth curve of strain JF2480, as well as other A. salmonicida strains, was determined (Figure 4). It appears that JF2480 grew as well as the other strains tested at $18{ }^{\circ} \mathrm{C}$. In addition, the strain JF2480 is the one with the best growth at $40{ }^{\circ} \mathrm{C}$ compared to other A. salmonicida mesophilic strains (Figure 4A), but this is not statistically significative ( $p=1.0000$ when comparing JF2480 with masoucida ATCC27013 for example). The difference in growth capacity is more pronounced at $41^{\circ} \mathrm{C}$, with strain JF2480 having the best growth compared to all other strains tested (Figure 4B). In this case, it is statistically significant $(p<0.0001$ when comparing JF2480 with Y567 or Y47 which are the second-best growers). It is interesting to note that the strain from the pectinolytica subspecies showed good growth at $18^{\circ} \mathrm{C}$ and $40^{\circ} \mathrm{C}$, but was much less important at $41^{\circ} \mathrm{C}$ $(p<0.0001$ when compared to A527). The other strains exhibited less fluctuating growth rate variations at the different temperatures. The growth of the A. salmonicida subspecies masoucida strain was one of the lowest at both $40{ }^{\circ} \mathrm{C}$ and $41^{\circ} \mathrm{C}$, which is coherent with previous results suggesting an intermediate lifestyle of this subspecies between psychrophilic and mesophilic [10].
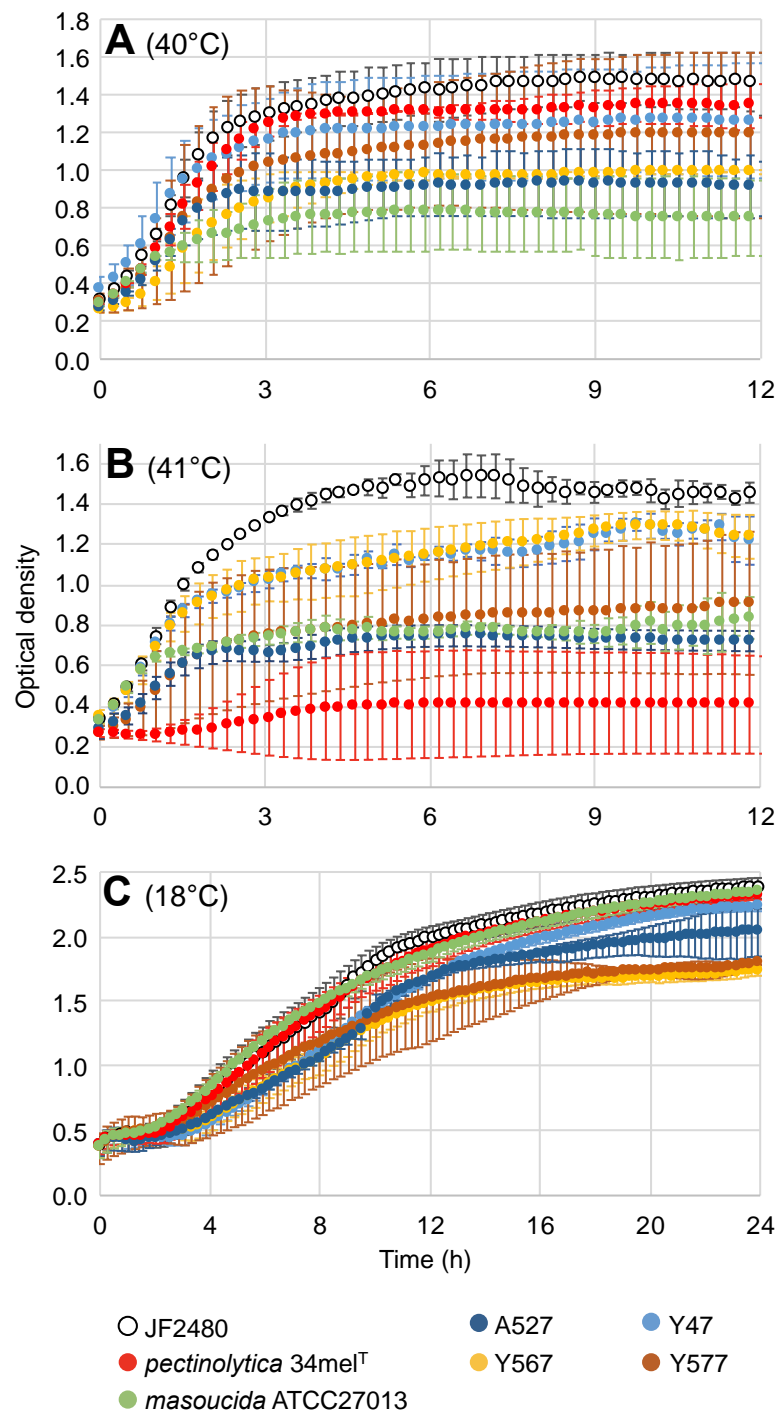

Figure 4. Growth curves for various $A$. salmonicida strains. The growth curves were determined at $40{ }^{\circ} \mathrm{C}(\mathrm{A}), 41{ }^{\circ} \mathrm{C}(\mathrm{B})$ and $18{ }^{\circ} \mathrm{C}$ (C) by measuring the optical density at $595 \mathrm{~nm}$. The means of two (A) and three biological replicates (B and $\mathbf{C}$ ) are shown for each strain. Each experiment was also performed in three technical replicates. 
Enzyme activities and details of the carbon sources utilized by the strain JF2480 are given in Tables S4 and S5. Extensive phenotypic characterization tests have been conducted demonstrating that strain JF2480 has a more diversified metabolism at $37^{\circ} \mathrm{C}$ than $25^{\circ} \mathrm{C}$ with additional carbon sources (D-manitol, D-glucose, palatinose, and D-sorbitol) that can be metabolized. However, even at $25^{\circ} \mathrm{C}$, the bacterium presented a wide range of metabolic activities.

\section{Discussion}

Historically, the bacterium A. salmonicida was known to infect salmonids, hence the origin of its name meaning "salmon killer" [51]. Since then, other bacteria belonging to A. salmonicida have been isolated from various fish species. In order to refine the taxonomy and respond to this diversity, different subspecies have been defined: salmonicida, smithia, masoucida, and achromogenes. The last subspecies to be defined, pectinolytica, made it possible to integrate into the salmonicida species an environmental and mesophilic bacterium, which can grow at a temperature of $37^{\circ} \mathrm{C}$, compared to other subspecies that are restricted to lower temperatures [4]. In recent years, several other mesophilic strains of A. salmonicida from the environment in India [10,11], and even human patients in Spain and Switzerland [14,18], have been isolated and characterized at the genomic level.

In this paper, a mesophilic strain of A. salmonicida isolated from a bird that died from septicemia, has been described and analyzed. The discovery of this strain shows that although the different strains are close evolutionarily (Figure 2), they have a wide range of hosts. The fact that psychrophilic strains are restricted to temperatures below $25^{\circ} \mathrm{C}$ considerably limits the hosts that can be infected by them and are therefore specialized in different cold water fish. Mesophilic strains can grow at $37^{\circ} \mathrm{C}$ (and even more, as shown with this study), and also at temperatures as low as those psychrophilic. This suggests that mesophilic strains have the potential to infect a wide range of hosts. This idea is supported by a previous study showing that mesophilic strains recovered from ill humans can also cause infection in mice [18]. Although strain JF2480 can be considered a pathogenic to Recurvirostra avocetta since it was abundantly present in 3 organs of a freshly dead bird, we do not know if the JF2480 strain is a polyvalent pathogen or if it is also, like the psychrophilic strains, specialized to specific hosts. On the other hand, the capacity of the JF2480 strain and other mesophilic strains to resist $D$. discoideum predation, a psychrophilic protozoan, opens the door to a wide range of hosts for mesophilic strains. Further infection experiments using mesophilic strains on fish will be mandatory in the future to help answer this question.

One of the reasons why the hosts that may be infected by mesophilic strains are still cryptic is that no strain has yet been isolated twice, thus making it impossible to determine confidently the real host range. Until very recently, A. salmonicida was mostly known as a pathogen of cold-water fish. It is therefore realistic to think that infections caused by these bacteria in other hosts have been falsely under-diagnosed. For example, we know that $A$. salmonicida can easily be diagnosed as A. hydrophila and that molecular analyses are needed to confirm the taxonomic identity of the strains with certainty $[9,18]$.

In addition to demystifying their host range, the isolation of other mesophilic strains of A. salmonicida will shed light on their pathogenicity. As discussed elsewhere, T3SS is known to be a virulence factor essential to the pathogenicity of strains of the salmonicida subspecies [52]. Although T3SS seems to also be important for virulence of mesophilic strains [18], it is likely not essential as some virulent strains, as JF2480 described in the present study, lack it. Even without having a T3SS, JF2480 bears two effectors related to this system: AexT, a binary toxin with actin ADP-ribosylation activity and GAP activity toward Rho, Rac, and Cdc42 [53] and AexU. It is unclear if these effectors are the remnant of a previous T3SS or if they can be translocated by another secretion system. In A. salmonicida subsp. salmonicida, the T3SS locus is known to be located on a thermosensitive region that can be lost when strains are grown at a high temperature $\left(>25^{\circ} \mathrm{C}\right)$ [45]. It is still unclear if a former T3SS in JF2480 may have been lost in such a way. 
As previously suggested [18], and reinforced by the present study, other genes also seem to be important for the virulence of mesophilic strains. These included five genes known to be virulence factors in other bacteria and potentially involved in necrotizing fasciitis by the mesophilic strains of $A$. salmonicida (Table 2). In the present study, we found two genes encoding zonula occludens toxin-like (Zot) in the genome of JF2480 (one partial and one likely complete), which is a virulence factor in $V$. cholerae [50]. In V. cholerae, Zot is encoded by the lysogenic phage СТХ $\Phi$ along with the genes producing the cholera toxin. In the case of strain JF2480, the genes encoding Zot toxins are not predicted to be encoded on a mobile DNA element such as a prophage. In addition, genes encoding cholera toxin do not have homologues in JF2480. The fact that the partial gene is found at the moment only in strain JF2480 among A. salmonicida, suggests a recent acquisition horizontally, and not a vertical transfer. This is interesting in the context where it has been shown that the strains of the psychrophilic subspecies A. salmonicida subsp. salmonicida can acquire exogenous DNA from other pathogens, such as Salmonella enterica [42,43] and Chlamydia suis [44]. The present study suggests that some mesophilic strains of $A$. salmonicida may also adapt by acquiring genetic material from other pathogens and thus play a role in the dispersal of these genes. Regarding the likely complete gene, given its broad distribution among Aeromonas species (including other strains of $A$. salmonicida), it is likely not solely responsible for the bird infection, although it might have contributed as a virulence factor.

Several genes involved in citrate metabolism were also found. The use of citrate was already shown to be important for virulence of pathogens such as Mycobacterium tuberculosis, Staphylococcus aureus, and $V$. cholerae [54-56]. Although there is currently no evidence of such involvement in JF2480, this may be a clue to help decipher why these genes are present in this strain.

\section{Conclusions}

In conclusion, the discovery and description of the JF2480 strain, the first known A. salmonicida strain isolated from a bird, has become further support that this species can infect a wider array of hosts than previously suspected, and that we need to rethink the way we perceive A. salmonicida's natural environment. In addition, the JF2480 strain is additional proof that the mesophilic group of the salmonicida species is more complex and diversified than the psychrophilic one. As already proposed [11,18], it is mandatory to continue this effort to isolate and describe new mesophilic A. salmonicida strains from different sources and hosts to finally have a global portrait of this bacterial species.

Supplementary Materials: The following are available online at http://www.mdpi.com/2076-2607/7/12/592/s1, Table S1. Genome sequences of Aeromonas used for the phylogenetic analysis; Table S2. Best-fit model of each partition; Table S3. Genes found to be unique to JF2480; Table S4. Phenotypic characterization of A. salmonicida strain JF2480 at $37^{\circ} \mathrm{C}$ using a VITEK 2 system from bioMerieux; Table S5. Phenotypic characteristics of A. salmonicida strain JF2480 using a API bioMerieux apparatus; Figure S1. Distribution of the genes encoding the Zot toxin in the genus Aeromonas and percentage of similarity when present.

Author Contributions: A.T.V., J.F. and S.J.C. contributed to the concepts and design of the study. A.T.V., A.B., J.F. and S.J.C. participated in the acquisition, analysis, and interpretation of the data. S.J.C., A.T.V. and J.F. drafted the manuscript. All authors reviewed the manuscript.

Funding: This work was supported by the Natural Sciences and Engineering Research Council of Canada (NSERC). ATV received a Postdoctoral Fellowship from NSERC. SJC is a research scholar of the Fonds de Recherche du Québec en Santé.

Conflicts of Interest: The authors declare no conflict of interest.

\section{References}

1. Martin-Carnahan, A.; Joseph, S. Aeromonadales ord. nov. In B, Bergey's Manual of Systematic Bacteriology SE - 12; Brenner, D., Krieg, N., Staley, J., Garrity, G., Boone, D., De Vos, P., Goodfellow, M., Rainey, F., Schleifer, K.-H., Eds.; Springer US: New York, NY, USA, 2005. 
2. Dallaire-Dufresne, S.; Tanaka, K.H.; Trudel, M.V.; Lafaille, A.; Charette, S.J. Virulence, genomic features, and plasticity of Aeromonas salmonicida subsp. salmonicida, the causative agent of fish furunculosis. Vet. Microbiol. 2014, 169, 1-7.

3. Austin, B.; Austin, D.A. Aeromonadaceae Representative (Aeromonas salmonicida). In Bacterial Fish Pathogens: Disease of Farmed and Wild Fish; Austin, B., Austin, D.A., Eds.; Springer International Publishing: New York, NY, USA, 2016.

4. Pavan, M.E.; Abbott, S.L.; Zorzopulos, J.; Janda, J.M. Aeromonas salmonicida subsp. pectinolytica subsp. nov., a new pectinase-positive subspecies isolated from a heavily polluted river. Int. J. Syst. Evol. Microbiol. 2000, 50, 1119-1124. [PubMed]

5. Abbott, S.L.; Cheung, W.K.; Kroske-Bystrom, S.; Malekzadeh, T.; Janda, J.M. Identification of Aeromonas strains to the genospecies level in the clinical laboratory. J. Clin. Microbiol. 1992, 30, 1262-1266.

6. Altwegg, M.; Steigerwalt, A.G.; Altwegg-Bissig, R.; Luthy-Hottenstein, J.; Brenner, D.J. Biochemical identification of Aeromonas genospecies isolated from humans. J. Clin. Microbiol. 1990, 28, 258-264.

7. Janda, J.M.; Abbott, S.L.; Khashe, S.; Kellogg, G.H.; Shimada, T. Further studies on biochemical characteristics and serologic properties of the genus Aeromonas. J. Clin. Microbiol. 1996, 34, 1930-1933.

8. Janda, J.M.; Abbott, S.L. The genus Aeromonas: Taxonomy, pathogenicity, and infection. Clin. Microbiol. Rev. 2010, 23, 35-73. [CrossRef]

9. Beaz-Hidalgo, R.; Alperi, A.; Bujan, N.; Romalde, J.L.; Figueras, M.J. Comparison of phenotypical and genetic identification of Aeromonas strains isolated from diseased fish. Syst. Appl. Microbiol. 2010, 33, 149-153. [CrossRef]

10. Vincent, A.T.; Trudel, M.V.; Freschi, L.; Nagar, V.; Gagne-Thivierge, C.; Levesque, R.C.; Charette, S.J. Increasing genomic diversity and evidence of constrained lifestyle evolution due to insertion sequences in Aeromonas salmonicida. BMC Genom. 2016, 17, 44. [CrossRef]

11. Vincent, A.T.; Rouleau, F.D.; Moineau, S.; Charette, S.J. Study of mesophilic Aeromonas salmonicida A527 strain sheds light on the species' lifestyles and taxonomic dilemma. FEMS Microbiol. Lett. 2017, 364. [CrossRef]

12. Nagar, V.; Shashidhar, R.; Bandekar, J.R. Prevalence, characterization, and antimicrobial resistance of Aeromonas strains from various retail food products in Mumbai, India. J. Food Sci. 2011, 76, M486-M492. [CrossRef]

13. Kamble, R. Aeromonas salmonicida furunculosis in an adult male. Int. J. Curr. Microbiol. App. Sci. 2015, 4, 59-63.

14. Ruppe, E.; Cherkaoui, A.; Wagner, N.; La Scala, G.C.; Beaulieu, J.Y.; Girard, M.; Frey, J.; Lazarevic, V.; Schrenzel, J. In vivo selection of a multidrug-resistant Aeromonas salmonicida during medicinal leech therapy. New Microbes New Infect. 2018, 21, 23-27. [CrossRef] [PubMed]

15. Tewari, R.; Dudeja, M.; Nandy, S.; Das, A.K. Isolation of Aeromonas salmonicida from human blood sample: A case report. J. Clin. Diagn. Res. 2014, 8, 139-140. [CrossRef]

16. Varshney, A.; Das, M.; Chaudhary, P.; Kumari, R.; Yadav, K. Aeromonas salmonicida as a causative agent for postoperative endophthalmitis. Middle East Afr. J. Ophthalmol. 2017, 24, 213-215. [CrossRef] [PubMed]

17. Yang, X.; Yang, Q.Q.; Guo, Q.Y.; Yi, C.Y.; Mao, H.P.; Lin, J.X.; Jiang, Z.P.; Yu, X.Q. Aeromonas salmonicida peritonitis after eating fish in a patient undergoing CAPD. Perit. Dial. Int. 2008, 28, 316-317.

18. Vincent, A.T.; Fernandez-Bravo, A.; Sanchis, M.; Mayayo, E.; Figueras, M.J.; Charette, S.J. Investigation of the virulence and genomics of Aeromonas salmonicida strains isolated from human patients. J. Mol. Epidemiol. Evol. Genet. Infect. Dis. 2019, 68, 1-9. [CrossRef]

19. Coil, D.; Jospin, G.; Darling, A.E. A5-miseq: An updated pipeline to assemble microbial genomes from Illumina MiSeq data. Bioinformatics 2015, 31, 587-589. [CrossRef]

20. Tatusova, T.; DiCuccio, M.; Badretdin, A.; Chetvernin, V.; Nawrocki, E.P.; Zaslavsky, L.; Lomsadze, A.; Pruitt, K.D.; Borodovsky, M.; Ostell, J. NCBI prokaryotic genome annotation pipeline. Nucleic acids Res. 2016, 44, 6614-6624. [CrossRef]

21. Seemann, T. Prokka: Rapid prokaryotic genome annotation. Bioinformatics 2014, 30, 2068-2069. [CrossRef]

22. Kristensen, D.M.; Kannan, L.; Coleman, M.K.; Wolf, Y.I.; Sorokin, A.; Koonin, E.V.; Mushegian, A. A low-polynomial algorithm for assembling clusters of orthologous groups from intergenomic symmetric best matches. Bioinformatics 2010, 26, 1481-1487. [CrossRef]

23. Li, L.; Stoeckert, C.J., Jr.; Roos, D.S. OrthoMCL: Identification of ortholog groups for eukaryotic genomes. Genome Res. 2003, 13, 2178-2189. [CrossRef] [PubMed] 
24. Contreras-Moreira, B.; Vinuesa, P. GET_HOMOLOGUES, a versatile software package for scalable and robust microbial pangenome analysis. Appl. Environ. Microbiol. 2013, 79, 7696-7701. [CrossRef] [PubMed]

25. Katoh, K.; Standley, D.M. MAFFT multiple sequence alignment software version 7: Improvements in performance and usability. Mol. Biol. Evol. 2013, 30, 772-780. [CrossRef] [PubMed]

26. Abascal, F.; Zardoya, R.; Telford, M.J. TranslatorX: Multiple alignment of nucleotide sequences guided by amino acid translations. Nucleic Acids Res. 2010, 38, W7-W13. [CrossRef] [PubMed]

27. Criscuolo, A.; Gribaldo, S. BMGE (Block Mapping and Gathering with Entropy): A new software for selection of phylogenetic informative regions from multiple sequence alignments. BMC Evol. Biol. 2010, 10, 210. [CrossRef] [PubMed]

28. Borowiec, M.L. AMAS: A fast tool for alignment manipulation and computing of summary statistics. PeerJ 2016, 4, e1660. [CrossRef]

29. Kalyaanamoorthy, S.; Minh, B.Q.; Wong, T.K.F.; von Haeseler, A.; Jermiin, L.S. ModelFinder: Fast model selection for accurate phylogenetic estimates. Nat. Methods 2017, 14, 587-589. [CrossRef]

30. Nguyen, L.T.; Schmidt, H.A.; von Haeseler, A.; Minh, B.Q. IQ-TREE: A fast and effective stochastic algorithm for estimating maximum-likelihood phylogenies. Mol. Biol. Evol. 2015, 32, 268-274. [CrossRef]

31. Hoang, D.T.; Chernomor, O.; von Haeseler, A.; Minh, B.Q.; Vinh, L.S. UFBoot2: Improving the ultrafast bootstrap approximation. Mol. Biol. Evol. 2018, 35, 518-522. [CrossRef]

32. Wattam, A.R.; Davis, J.J.; Assaf, R.; Boisvert, S.; Brettin, T.; Bun, C.; Conrad, N.; Dietrich, E.M.; Disz, T.; Gabbard, J.L.; et al. Improvements to PATRIC, the all-bacterial bioinformatics database and analysis resource center. Nucleic Acids Res. 2017, 45, D535-D542. [CrossRef]

33. Abby, S.S.; Rocha, E.P.C. Identification of protein secretion systems in bacterial genomes using macsyfinder. Methods Mol. Biol. 2017, 1615, 1-21. [PubMed]

34. Huerta-Cepas, J.; Forslund, K.; Coelho, L.P.; Szklarczyk, D.; Jensen, L.J.; von Mering, C.; Bork, P. Fast Genome-Wide Functional Annotation through Orthology Assignment by eggNOG-Mapper. Mol. Biol. Evol. 2017, 34, 2115-2122. [CrossRef] [PubMed]

35. Froquet, R.; Cherix, N.; Burr, S.E.; Frey, J.; Vilches, S.; Tomas, J.M.; Cosson, P. Alternative host model to evaluate Aeromonas virulence. Appl. Environ. Microbiol. 2007, 73, 5657-5659. [CrossRef] [PubMed]

36. Cornillon, S.; Pech, E.; Benghezal, M.; Ravanel, K.; Gaynor, E.; Letourneur, F.; Bruckert, F.; Cosson, P. Phg1p is a nine-transmembrane protein superfamily member involved in dictyostelium adhesion and phagocytosis. J. Biol. Chem. 2000, 275, 34287-34292. [CrossRef]

37. Mercanti, V.; Charette, S.J.; Bennett, N.; Ryckewaert, J.J.; Letourneur, F.; Cosson, P. Selective membrane exclusion in phagocytic and macropinocytic cups. J. Cell Sci. 2006, 119, 4079-4087. [CrossRef]

38. Baldwin, T.; Sakthianandeswaren, A.; Curtis, J.M.; Kumar, B.; Smyth, G.K.; Foote, S.J.; Handman, E. Wound healing response is a major contributor to the severity of cutaneous leishmaniasis in the ear model of infection. Parasite Immunol. 2007, 29, 501-513. [CrossRef]

39. Joest, R. Junge Säbelschnäbler (Recurvirostra avosetta L.) in unterschiedlichen Klimazonen: Physiologische und ethologische Anpassungen an ökologische Bedingungen in Norddeutschland und Südspanien; Christian-Albrechts Universität Kiel: Kiel, Germany, 2003.

40. Vincent, A.T.; Le Breton, A.; Bernatchez, A.; Gagne-Thivierge, C.; Paquet, V.E.; Thibault, E.; Charette, S.J.; Gantelet, H. Draft genome sequences of four Aeromonas salmonicida subsp. achromogenes Strains, 23051, 23053, 23055, and 23056, Isolated from senegalese sole (Solea senegalensis). Microbiol. Resour. Announc. 2019, 8. [CrossRef]

41. Trudel, M.V.; Vincent, A.T.; Attere, S.A.; Labbe, M.; Derome, N.; Culley, A.I.; Charette, S.J. Diversity of antibiotic-resistance genes in Canadian isolates of Aeromonas salmonicida subsp. salmonicida: Dominance of pSN254b and discovery of pAsa8. Sci. Rep. 2016, 6, 35617. [CrossRef]

42. Vincent, A.T.; Trudel, M.V.; Paquet, V.E.; Boyle, B.; Tanaka, K.H.; Dallaire-Dufresne, S.; Daher, R.K.; Frenette, M.; Derome, N.; Charette, S.J. Detection of variants of the pRAS3, pAB5S9, and pSN254 plasmids in Aeromonas salmonicida subsp. salmonicida: Multidrug resistance, interspecies exchanges, and plasmid reshaping. Antimicrob. Agents Chemother. 2014, 58, 7367-7374. [CrossRef]

43. Massicotte, M.A.; Vincent, A.T.; Schneider, A.; Paquet, V.E.; Frenette, M.; Charette, S.J. One Aeromonas salmonicida subsp. salmonicida isolate with a pAsa5 variant bearing antibiotic resistance and a pRAS3 variant making a link with a swine pathogen. Sci. Total. Environ. 2019, 690, 313-320. [CrossRef] 
44. Costa, T.R.; Felisberto-Rodrigues, C.; Meir, A.; Prevost, M.S.; Redzej, A.; Trokter, M.; Waksman, G. Secretion systems in Gram-negative bacteria: Structural and mechanistic insights. Nat. Rev. Microbiol. 2015, 13, 343-359. [CrossRef] [PubMed]

45. Daher, R.K.; Filion, G.; Tan, S.G.; Dallaire-Dufresne, S.; Paquet, V.E.; Charette, S.J. Alteration of virulence factors and rearrangement of pAsa5 plasmid caused by the growth of Aeromonas salmonicida in stressful conditions. Vet. Microbiol. 2011, 152, 353-360. [CrossRef] [PubMed]

46. Froquet, R.; Lelong, E.; Marchetti, A.; Cosson, P. Dictyostelium discoideum: A model host to measure bacterial virulence. Nat. Protoc. 2009, 4, 25-30. [CrossRef] [PubMed]

47. Studer, N.; Frey, J.; Vanden Bergh, P. Clustering subspecies of Aeromonas salmonicida using IS630 typing. BMC Microbiol. 2013, 13, 36. [CrossRef] [PubMed]

48. Zeng, W.B.; Chen, W.B.; Yan, Q.P.; Lin, G.F.; Qin, Y.X. Hemerythrin is required for Aeromonas hydraphlia to survive in the macrophages of Anguilla japonica. Genet. Mol. Res: GMR 2016, 15. [CrossRef]

49. Eshghi, A.; Lourdault, K.; Murray, G.L.; Bartpho, T.; Sermswan, R.W.; Picardeau, M.; Adler, B.; Snarr, B.; Zuerner, R.L.; Cameron, C.E. Leptospira interrogans catalase is required for resistance to $\mathrm{H}_{2} \mathrm{O}_{2}$ and for virulence. Infect. Immun. 2012, 80, 3892-3899. [CrossRef]

50. Waldor, M.K.; Mekalanos, J.J. Lysogenic conversion by a filamentous phage encoding cholera toxin. Science 1996, 272, 1910-1914. [CrossRef]

51. Martin-Carnahan, A.; Joseph, S.W. Aeromonas. In Bergey's Manual of Systematics of Archaea and Bacteria; Whitman, W.B., Rainey, F., Kämpfer, P., Trujillo, M., Chun, J., DeVos, P., Hedlund, B., Dedysh, S., Eds.; Wiley: Hoboken, NJ, USA, 2015; pp. 1-44. [CrossRef]

52. Frey, J.; Origgi, F.C. Type III secretion system of aeromonas salmonicida undermining the host's immune response. Front. Mar. Sci. 2016, 3. [CrossRef]

53. Fehr, D.; Burr, S.E.; Gibert, M.; d'Alayer, J.; Frey, J.; Popoff, M.R. Aeromonas exoenzyme T of Aeromonas salmonicida is a bifunctional protein that targets the host cytoskeleton. J. Biol. Chem. 2007, 282, 28843-28852. [CrossRef]

54. Ding, Y.; Liu, X.; Chen, F.; Di, H.; Xu, B.; Zhou, L.; Deng, X.; Wu, M.; Yang, C.G.; Lan, L. Metabolic sensor governing bacterial virulence in Staphylococcus aureus. Proc. Natl. Acad. Sci. USA 2014, 111, E4981-E4990. [CrossRef]

55. Minato, Y.; Fassio, S.R.; Wolfe, A.J.; Hase, C.C. Central metabolism controls transcription of a virulence gene regulator in Vibrio cholerae. Microbiology 2013, 159, 792-802. [CrossRef] [PubMed]

56. Arora, G.; Chaudhary, D.; Kidwai, S.; Sharma, D.; Singh, R. Cite enzymes are essential for mycobacterium tuberculosis to establish infection in macrophages and guinea pigs. Front. Cell. Infect. Microbiol. 2018, 8, 385. [CrossRef] [PubMed]

(C) 2019 by the authors. Licensee MDPI, Basel, Switzerland. This article is an open access article distributed under the terms and conditions of the Creative Commons Attribution (CC BY) license (http://creativecommons.org/licenses/by/4.0/). 